\title{
OPTIMIZING THE LOCATION OF URBAN CHARGING STATIONS FOR ELECTRIC VEHICLES: CASE STUDY OF THE CITY OF TYUMEN, RUSSIAN FEDERATION
}

\author{
ANASTASIYA GORBUNOVA \& ILYA ANISIMOV \\ Department of Motor Transport Operation, Industrial University of Tyumen, Russian Federation
}

\begin{abstract}
An urgent area of the transport industry is the development of electric vehicles. This trend requires the development of charging infrastructure. Currently, this is developing, but not in all countries. A small fleet of electric vehicles results in a limited number of installed charging stations. The reason for this is their low profitability and lack of support from public authorities, as partially observed in the Russian Federation. In this case, an important task is identifying the optimal location of the limited number of charging stations so that they meet the maximum demand from the electric vehicle owners. A review of previous studies on modeling the optimal location of charging stations in cities showed several basic approaches. These are based on models of the maximum coverage of demand and p-median, as well as models that take into account the road network features, such as car parking. The models, as a rule, do not interact with each other and do not consider the high building density or the complexity of the approach to the charging station among others. Therefore, the purpose of this study is to develop a new model for the location of charging stations in the city that takes into account the characteristics of the road network, the traffic flow at its nodes and places of attraction for the population. It minimizes the total cost of operating the charging infrastructure. The model is developed on the basis of two stages of research. The first stage showed the applicability of the p-median model to the location of charging stations. This model is adjusted using decision variables that characterize the capital cost of building a charging station and the features of car parking.
\end{abstract}

Keywords: electric vehicle, charging station, charging infrastructure, model of the optimal location, capital costs, operating costs, features of the road network, traffic flow, decision variables.

\section{INTRODUCTION}

Electrification of road transport is an urgent area of the automotive industry development [1], [2]. At the end of 2019, the number of electric vehicles in the world reached 7.1 million. According to the forecast of analytical agencies, this number will exceed 160 million units in 2030 [3]-[5]. The active development of the new vehicle type requires the creation of a charging infrastructure.

At the present time, the world's charging infrastructure is expanding, but not in all countries [6]. A small fleet of electric vehicles results in a limited number of installed charging stations. The reason for this is their low profitability and lack of support from public authorities; partially this is observed in the Russian Federation. In this case, an important task is the optimal location of the limited number of charging stations so that they maximize the demand of the electric vehicle owners [7].

The optimal location of charging stations in cities is a current task of transport planning. The aim of such studies is to develop a model for the optimal location of charging stations. The main approaches to the creation of these models are based on the principles developed by Daskin [8], [9]. He used the maximum demand coverage and p-median models for locating the important urban infrastructure. These models aim to reduce the operating costs of the facilities. Then, the maximum demand coverage model was applied in the studies of Gimenez-Gaydou et al. [7] and Frade et al. [10]. These authors adapted the Daskin model to determine the optimal location of slow charging stations in urban areas. In the model 
developed by Frade et al., a charging station is located in each selected area of the city [10]. This location does not depend on the characteristics of the electric vehicle operation and charge. Gimenez-Gaydou et al. locate the charging stations based on a set of parking data during the day and night. In this case, the number of charging stations was reduced so that they were located in only one of two possible places [7]. Ghamami et al. also adopt a similar approach [11] locating charging stations only near office centers and taking into account: the number of car parking spaces; the number of employees in the office center who have electric vehicles; the distance between the car parking and the office center; the capital cost of the charging station. In some cases, the application of these models is difficult due to the lack of a sufficient number of parking spaces, the complicated access road to the charging station and the features of the population movement.

A model for the optimal location of charging stations in the city can also be based on the p-median model. Initially, the latter was used to determine the location of charging/battery exchange stations for commercial electric vehicles [12]. Then, He et al. demonstrated the applicability of the p-median model to the location of public charging stations for electric vehicles [13]. The initial data for this model were places of attraction for the population, as well as the distances between them and the location of charging stations. The location was based on minimizing the considered distances and maximizing the demand coverage. However, these models do not consider features of the road network.

Such data and features of population movement are included in a model for the optimal location of charging stations, developed using agent-based modeling [14]. In this case, the location of the charging station was based on the places of the electric vehicle owner concentration in the simulated city area. The initial data for the calculation were a scheme of the city's road network, destination and departure places of the electric vehicle owners and features of their behavior. The resulting model enables finding the concentration places of the electric vehicle owners and assesses their movements, taking into account changes in the initial data. However, the application of this model is difficult due to the large amount of initial information required for its creation.

The location of the network nodes and the traffic flow in them was considered in the research of Ge et al. [15]. The authors suggested that the optimal location of a charging station corresponds to the minimum total cost of its operation. Therefore, in this model, the authors took into account not only the characteristics of the road network and the traffic flow on its sections, but also the structure of the urban distribution network. The cost of operating a charging station is minimized by its location near existing transport infrastructure facilities, in particular gas stations [16]-[18]. However, the application of these approaches does not always maximize the traffic flow that passes through the installed charging station.

Thus, models for the optimal location of the charging station in cities have been developed. However, accounting for features of the population movement, high building density and a lack of a sufficient number of parking spaces requires the development of a new model. This will also take into account both places of attraction for the population, as well as features of the road network and the traffic flow on its sections. The model will minimize the capital and operating costs of the charging infrastructure, as well as the operating costs for electric vehicle owners.

\section{METHODOLOGY}

The model for the optimal location of charging stations in the city aims to minimize its capital and operating costs, as well as operating costs for electric vehicle owners. Therefore, its development took into account the following statements: 
- minimizing the capital costs of a charging station requires its location near large urban facilities that have their own transformer station [14];

- minimizing the operating costs of the charging infrastructure requires reducing its downtime and increasing its profitability;

- minimizing the operating costs for electric vehicle owners requires reducing the time and distance to the nearby charging station [8], [10].

Additional conditions for the development of the model were the following statements:

- $\quad$ availability of free parking space;

- no complicated access road to the charging station (bridges, circular traffic, oneway traffic, etc.).

The new model for the optimal location of charging stations in a city was developed in two stages. The aim of the first stage was to minimize the operating costs for charging network owners and owners of electric vehicles. In this case, the model of maximum demand coverage was assessed by its applicability to the location of charging stations in cities of the Russian Federation. It reduces downtime for charging stations by maximizing demand. At the same time, it limits the empty runs of vehicles by introducing an additional model parameter - the coverage distance [6]. The target function of this model is given by the eqn:

$$
\sum_{i \in I} h_{i} \cdot Z_{i} \rightarrow \max ,
$$

where $h_{i}$ is demand at node $i \epsilon I$ of the considered road network, vehicle/hour; $Z_{i}$ is a decision variable which can be equal to 1 or 0 . If the nearby charging station is within the coverage distance $D_{c}$, then $Z_{i}=1$. If there are no charging stations within the coverage distance, then $Z_{i}=0$.

The aim of the first stage can also be achieved using the p-median model [6]. In this case, the minimized target function is the operating costs for electric vehicle owners. At the same time, demand at the node should also reach its maximum. The target function of this model is given by the eqn:

$$
\sum_{i \in I} h_{i} \cdot d_{i j} \cdot Y_{i j} \rightarrow \text { min provided that } Y_{i j}=1,
$$

where $d_{i j}$ is distance between the demand node $i \epsilon I$ and the location of the charging station $j \epsilon J$, $\mathrm{m} ; Y_{i j}$ is a decision variable which can be equal to 1 or 0 . If the demand at node $i \epsilon I$ is covered by the charging station located at node $j \epsilon J$, then $Y_{i j}=1$; if the demand is not covered, then $Y_{i j}=0$.

A comparative analysis of the first stage results will enable choosing a model for determining the location of charging stations. The second stage of the study is to adapt the selected model. In this case, the target is to minimize the capital costs of the charging station and fulfill the additional conditions of the model. This problem is solved by introducing additional decision variables. They enable selecting the optimal location of the charging station, taking into account all previously extended positions.

The location of charging stations is transferred from the nodes of the road network to the nearby car parking, taking into account a complicated access road. Additionally, the following decision variables are calculated:

- $\quad C_{j}$ is a decision variable aimed at minimizing capital costs; it enables assessing the presence of a transformer substation in the proposed location of the charging station. If the location of the charging station has a transformer station, $C_{j}=1$. If there is no transformer substation, then $C_{j}=0$. 
- $\quad P_{j}$ is a decision variable aimed at evaluating parking spaces; it enables estimating the probability of free parking spaces. If there are no more than 50 parking spaces, then $P_{j}=0$. If there are at least 50 but not more than 100 parking spaces, then $P_{j}=1$. If there are more than 100 parking spaces, then $P_{j}=2$ ).

The sum of the decision variables should tend to a maximum. The location of the charging station is based on the data obtained from the solution of the system of eqns:

$$
\left\{\begin{array}{c}
\left(C_{j}+P_{j}\right) \rightarrow \max \\
h_{i} \rightarrow \max
\end{array}\right.
$$

\section{DESCRIPTION OF THE EXISTING CHARGING INFRASTRUCTURE IN TYUMEN} Currently, Tyumen has developed regional charging infrastructure in the Russian Federation. It includes six public charging stations located in different areas of the city (Fig. 1).

Analysis of the number of charging sessions, performed at each of the public charging stations (Fig. 2), showed that they are unevenly distributed.

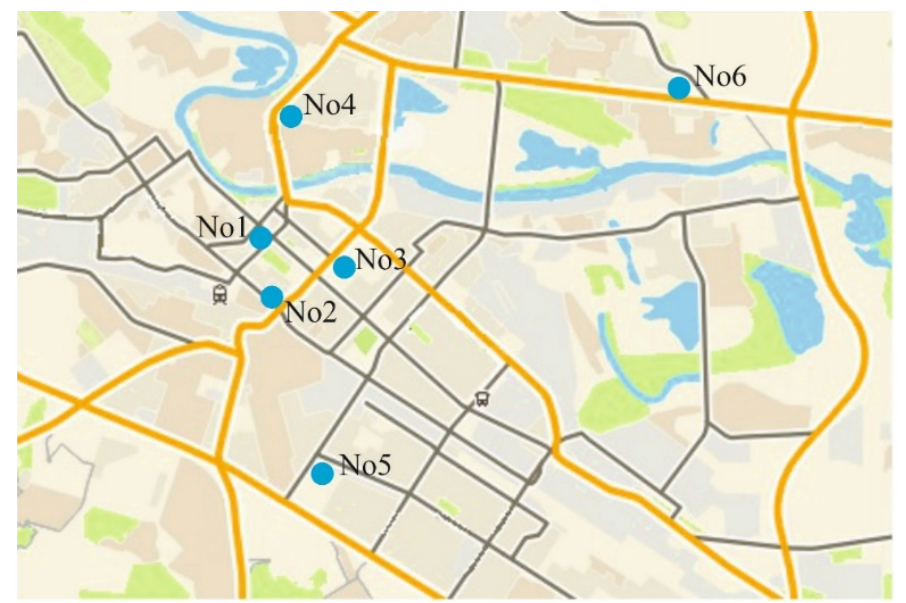

Figure 1: Layout of public charging stations for electric vehicles in Tyumen.

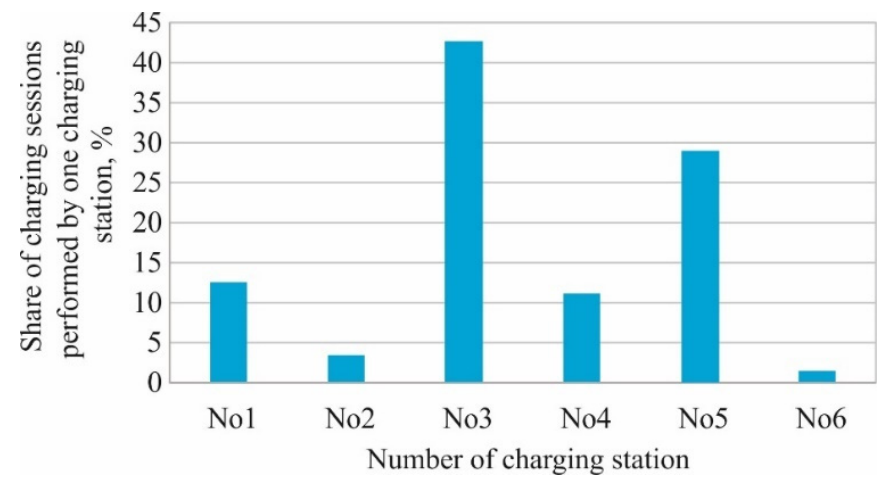

Figure 2: Share of charging sessions performed by each charging station per month in Tyumen. 
This distribution of charging sessions is due to low transport demand or complicated access roads to charging stations No. 2 and No. 6. Therefore, this arrangement of charging stations was optimized using the developed approach. This will reduce downtime for charging stations and distribute demand more evenly.

\section{OPTIMIZING THE LOCATION OF CHARGING STATIONS IN TYUMEN}

Preliminarily, the territory of Tyumen was represented using the road network schemes. The scheme included nodes, a transport demand at them and distances (Fig. 3).

The maximum coverage model includes coverage distance as an input. This value was determined in accordance with the regulations of the Russian Federation, which govern the distance from the car parking to the destination. It was taken no more than $800 \mathrm{~m}$. As a result, a comparison of this value with the distances between all nodes shown in Fig. 3 was performed. The obtained values were entered into the matrix, a fragment of which is presented in Table 1.

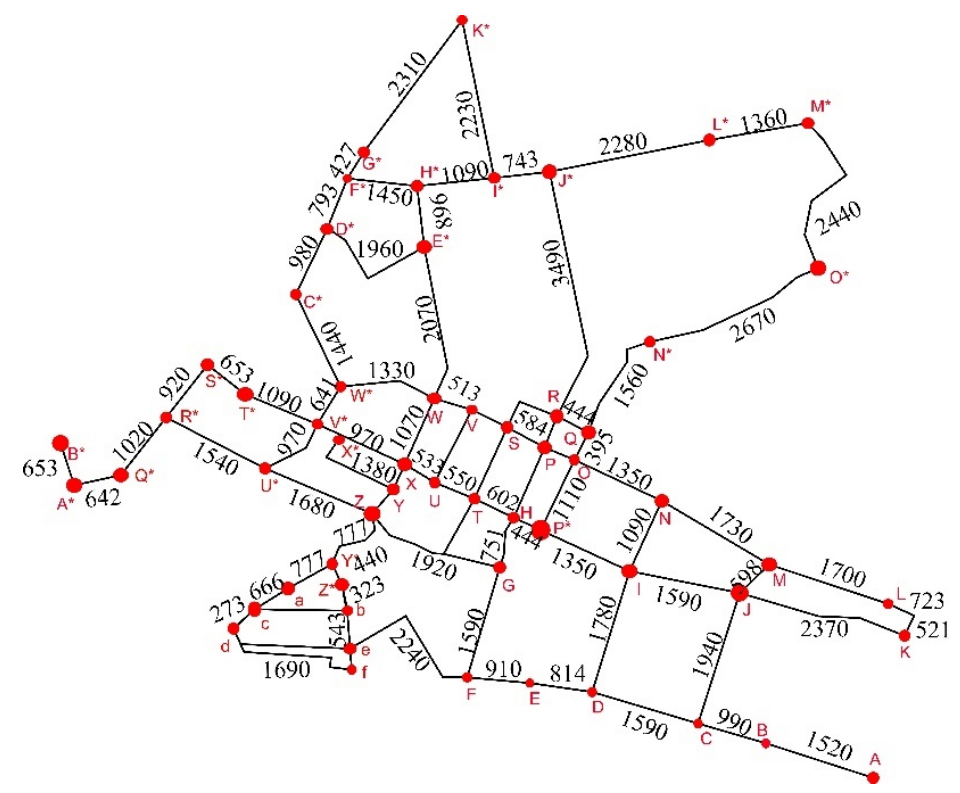

Figure 3: Scheme of the road network in Tyumen.

Table 1: Fragment of the covered node matrix.

\begin{tabular}{|c|c|c|c|c|c|c|c|c|c|c|c|}
\hline \multirow{2}{*}{$\begin{array}{l}\text { Charging } \\
\text { station } \\
\text { location }\end{array}$} & \multicolumn{9}{|c|}{ Covered node } & \multirow{2}{*}{$\begin{array}{c}\text { Total } \\
\text { number of } \\
\text { nodes } \\
\text { covered }\end{array}$} & \multirow{2}{*}{$\begin{array}{l}\text { Maximum covered } \\
\text { transport demand, } \\
\text { vehicles/hour }\end{array}$} \\
\hline & G & $\mathrm{H}$ & $\mathrm{O}$ & $\mathrm{P}$ & Q & $\mathrm{R}$ & $\mathrm{S}$ & $\mathrm{T}$ & $\mathrm{V}$ & & \\
\hline A & 0 & 0 & 0 & 0 & 0 & 0 & 0 & 0 & 0 & 1 & 609 \\
\hline $\mathrm{H}$ & 1 & 1 & 0 & 1 & 0 & 0 & 0 & 1 & 0 & 4 & 19,665 \\
\hline $\mathrm{P}$ & 0 & 0 & 0 & 1 & 1 & 0 & 1 & 1 & 0 & 4 & 16,091 \\
\hline $\mathrm{R}$ & 0 & 0 & 0 & 1 & 1 & 1 & 1 & 0 & 0 & 4 & 15,558 \\
\hline $\mathrm{S}$ & 0 & 0 & 0 & 1 & 1 & 1 & 0 & 0 & 1 & 4 & 16,114 \\
\hline
\end{tabular}




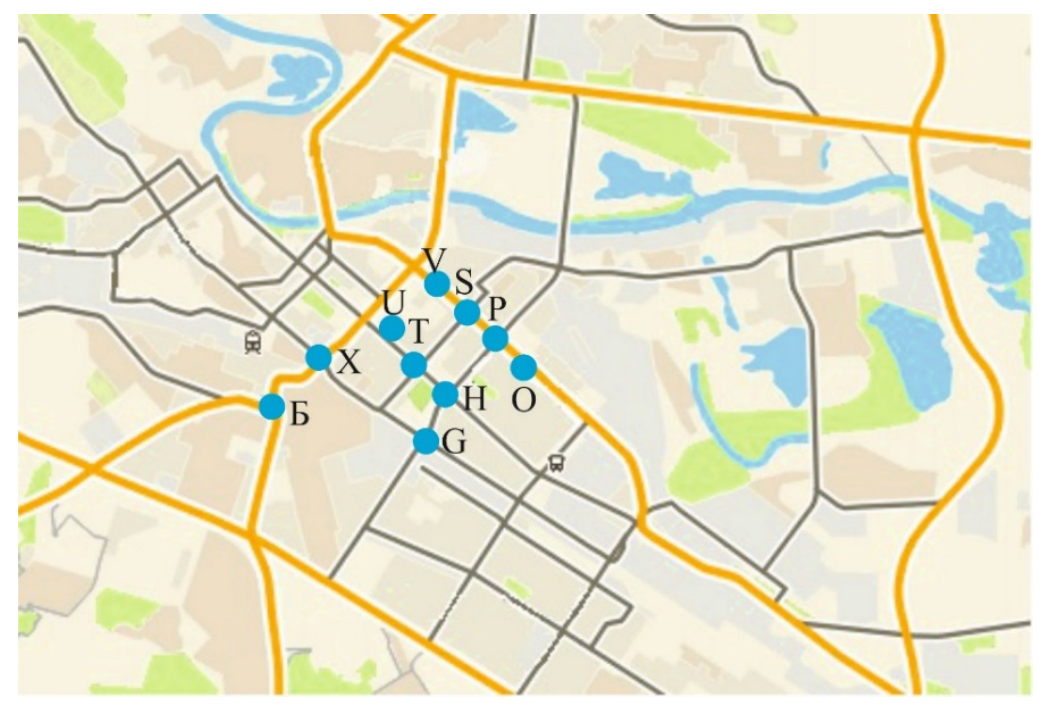

Figure 4: Location of charging stations according to the maximum demand coverage model.

Data processing enables identifying ten locations of charging stations. They cover the largest number of neighboring nodes and the largest transport demand. The locations of charging stations according to the maximum demand coverage model are shown in Fig. 4.

The results showed that there is a high concentration of charging stations in some sections of the road network. This location distribution will be adjusted according to the additionally entered decision variables of the model.

The p-median model took into account distances between the location of the charging station and the demand node in the calculation. Therefore, there was no distance limitation. The model was developed on the basis of calculating the product of two matrices: the transport demand matrix and the distance matrix. A fragment of these calculation results is presented in Table 2 .

The minimum value of the total in the covered node corresponded to the location of the first charging station. All the values in the charging station location were equal to zero; then, the authors found the next minimum value of the total in the covered node. Thus, the step-by-step selection of the charging station locations showed, as in the previous case, ten nodes (Fig. 5).

Table 2: Fragment of the resulting matrix.

\begin{tabular}{|c|c|c|c|c|c|}
\hline \multirow{2}{*}{$\begin{array}{c}\text { Charging } \\
\text { station } \\
\text { location }\end{array}$} & \multicolumn{5}{|c|}{ Covered node } \\
\hline & G & $\mathrm{H}$ & $\mathrm{O}$ & $\mathrm{P}$ & Q \\
\hline $\mathrm{A}$ & 4515126 & 4673466 & 4098570 & 4368966 & 4339125 \\
\hline $\mathrm{H}$ & 3545471 & 0 & 7336434 & 5240310 & 9201229 \\
\hline $\mathrm{P}$ & 8592237 & 5124870 & 2049948 & 0 & 3873663 \\
\hline $\mathrm{R}$ & 7625280 & 5086900 & 2835820 & 1335100 & 1500720 \\
\hline $\mathrm{S}$ & 10154085 & 7035182 & 4269284 & 2425352 & 4269284 \\
\hline Total & 724122463 & 629255376 & 731139368 & 692028158 & 758357633 \\
\hline
\end{tabular}




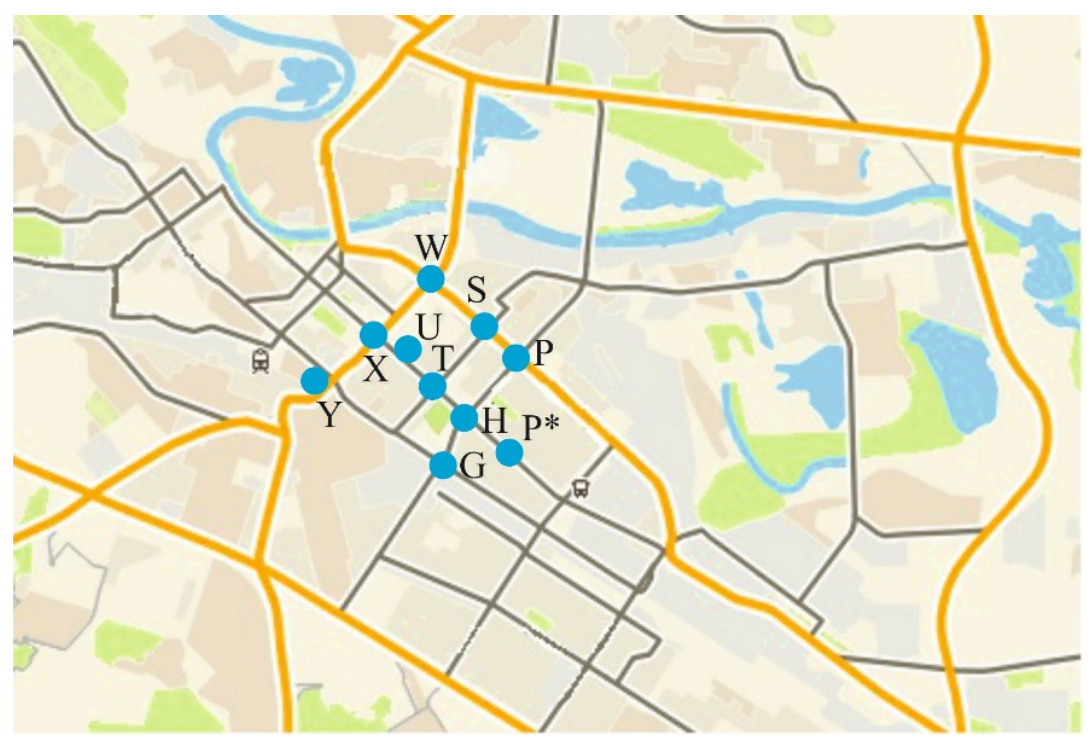

Figure 5: Location of charging stations according to the p-median model.

This model, as well as the maximum demand coverage model, showed a high concentration of charging stations in some sections of the road network.

The models were compared on the total transport demand at the charging stations. As a result, the total transport demand at the nodes of charging stations for the maximum coverage model was 41,813 vehicles/hour, and for the p-median model, 44,538 vehicles/hour. Therefore, the authors concluded that the p-median model is applicable to the location of charging stations in Tyumen.

The locations of charging station were analyzed with additional decision variables that indicate the presence of a transformer station and parking spaces. These decision variables for the p-median model nodes are presented in Table 3.

Table 3: Decision variables of the charging station locations.

\begin{tabular}{|c|c|c|c|c|}
\hline $\begin{array}{c}\text { Charging station } \\
\text { location }\end{array}$ & $\mathrm{C}_{\mathrm{j}}$ & $\mathrm{P}_{\mathrm{j}}$ & $\begin{array}{c}\text { Sum of } \\
\text { decision } \\
\text { variables }\end{array}$ & $\begin{array}{c}\text { Transport } \\
\text { demand in } \\
\text { the node, } \\
\text { vehicles/hour }\end{array}$ \\
\hline $\mathrm{P}^{*}$ & 0 & 0 & 0 & 4,617 \\
\hline $\mathrm{G}$ & 0 & 0 & 0 & 4,228 \\
\hline $\mathrm{H}$ & 1 & 1 & 2 & 4,721 \\
\hline $\mathrm{P}$ & 0 & 0 & 0 & 4,717 \\
\hline $\mathrm{S}$ & 0 & 0 & 0 & 4,153 \\
\hline $\mathrm{T}$ & 0 & 0 & 0 & 4,099 \\
\hline $\mathrm{U}$ & 1 & 2 & 3 & 3,041 \\
\hline $\mathrm{W}$ & 0 & 1 & 1 & 4,912 \\
\hline $\mathrm{X}$ & 1 & 2 & 3 & 3,108 \\
\hline $\mathrm{Y}$ & 0 & 1 & 1 & 5,042 \\
\hline
\end{tabular}




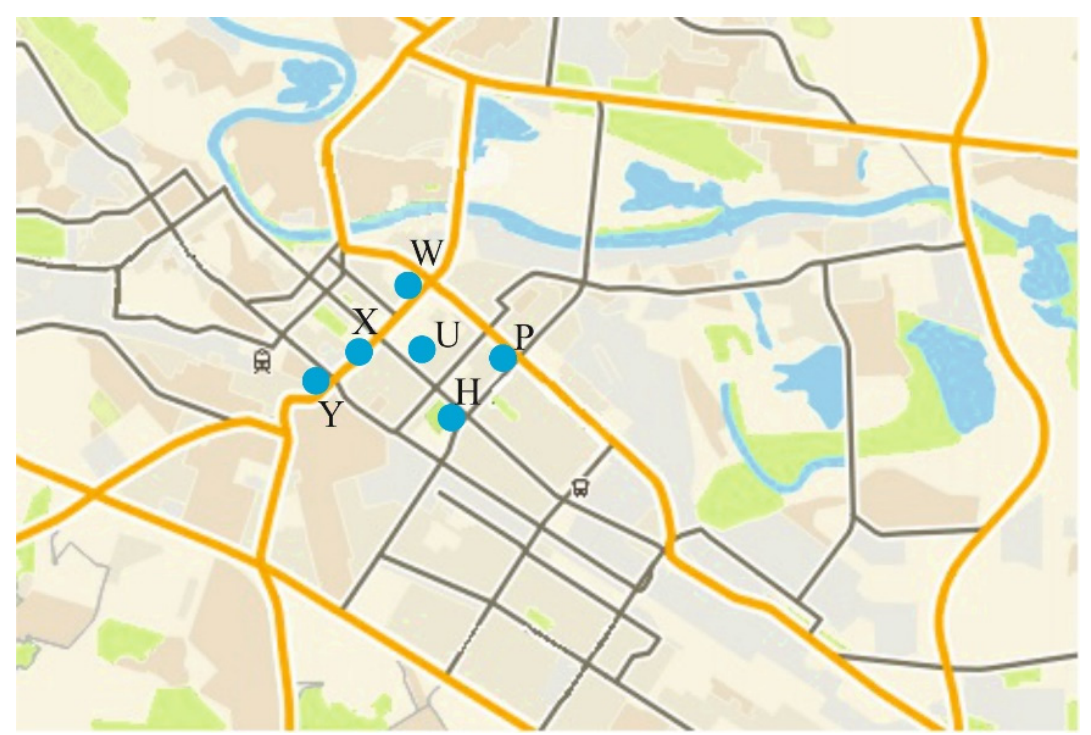

Figure 6: Location of charging stations in Tyumen.

Nodes with the highest sum of decision variables were chosen for the location of the charging stations. However, there were five of these nodes. They reduce charging station capital costs and operating costs for electric vehicle owners. At the same time, these locations have high demand. The location of the sixth charging station was chosen on the basis of the maximum transport demand at this node. It will increase the demand for the charging station and reduce empty runs for electric vehicle owners. As a result, the location of the charging stations in Tyumen is shown in Fig. 6.

The applicability of the developed model to the location of charging stations in other cities of the Russian Federation will be assessed during the next stages of research. Then the software will be developed for its practical application.

\section{CONCLUSIONS}

This article describes the development and application of a model for the optimal location of charging stations in the city. It takes into account the possibility of the absence of a permanent workplace for owners of electric vehicles, a complex access road to the charging station, the availability of free parking spaces and other features of the road network. An analysis of previous studies in the area of the charging station location in the city showed that such a model has not been developed until now.

The target function of the model was to minimize the total costs, both in the operation of the charging infrastructure and in the operation of electric vehicles. The development of this model was based on the statements that:

- minimizing the capital costs requires the location of a charging station near transformer substations and car parking;

- minimizing the operating costs of the charging infrastructure requires an increase in traffic flow passing through the charging station during the day;

- minimizing operating costs for electric vehicle owners requires reducing vehicle empty runs. 
Additional conditions for developing the model were:

- $\quad$ availability of free parking spaces;

- not complicated access road to the charging station.

The model was developed in two stages. The first stage consisted of comparing the applicability of the p-median and maximum coverage model to the location of charging stations in the city. The study of the charging station locations in Tyumen showed the effectiveness of the p-median model. Then the model was adjusted with the additionally developed decision variables. They are associated with the presence of a transformer station and free parking spaces near the charging station. The introduction of these variables enables identifying the most optimal locations for the charging stations.

The applicability of the developed model to the location of charging stations in other cities of the Russian Federation will be assessed during the next stages of research. Then the software will be developed for its practical application.

\section{ACKNOWLEDGEMENT}

The work was supported by the Ministry of Science and Higher Education, contract № 08252020-0014.

\section{REFERENCES}

[1] Ionescu, G., Apostol, T., Rada, E.C., Ragazzi, M. \& Torretta, V., Critical analysis of strategies for PM reduction in urban areas. UPB Scientific Bulletin, Series D: Mechanical Engineering, 75(2), pp. 175-186, 2013.

[2] Anisimov, I.A., Burakova, A.D. \& Burakova, L.N., Increasing the efficiency of electricity production from renewable source for charging electric vehicles. 2018 International Multi-Conference on Industrial Engineering and Modern Technologies: proceedings of conference, 18393143, 2020.

DOI: 10.1109/FarEastCon.2018.8602620.

[3] Istrate, I.A., Oprea, T., Rada, E.C. \& Torretta, V., Noise and air pollution from urban traffic. WIT Transactions on Ecology and the Environment, 191, pp. 1381-1389, 2014.

[4] Funke, S., Sprei, F., Ghann, T. \& Plotz, P., How much charging infrastructure do electric vehicles need? A review of the evidence and international comparison. Transportation research part D: transport and environment, 77, pp. 224-242, 2019.

[5] Gorbunova, A., Anisimov, I. \& Magaril, E., Studying the formation of the charging session number at public charging stations for electric vehicles. Sustainability, 12, 5571. DOI: $10.3390 /$ su12145571.

[6] Innovation Outlook: Smart charging for electric vehicles. International Renewable Energy Agency. https://www.irena.org/publications/2019/May/Innovation-OutlookSmart-Charging. Accessed on: 17 Jul. 2020.

[7] Gimenez-Gaydou, D.A., Ribeiro, A.N., Gutierrea, J. \& Antunes, A.P., Optimal location of battery electric vehicle charging stations in urban areas: A new approach. International Journal of Sustainable Transportation, 10, pp. 393-405, 2016.

[8] Daskin, M.S., Network and Discrete Location. Models, Algorithms, and Applications, John Wiley \& Sons: New Jersey, pp. 124-362, 2013.

[9] Daskin, M.S., What you should know about location modelling. Naval Research Logistics, 55(4), pp. 283-294, 2008. 
[10] Frade, I., Ribeiro, A., Goncalves, G.A. \& Antunes, A.P., Optimal location of charging stations for electric vehicles in a neighborhood in Lisbon, Portugal. Transportation Research Record Journal of the Transportation Research Board, 2252(1), pp. 91-98, 2011.

[11] Ghamami, M., Nie, Y. \& Zockaie. A., Planning charging infrastructure for plug-in electric vehicles in city canters. International Journal of Sustainable Transportation, 10, pp. 343-353, 2016.

[12] Ko, J. \& Shim, J.S., Locating battery exchange stations for electric taxis: A case study of Seoul, South Korea. International Journal of Sustainable Transportation, 10, pp. 139-146, 2016.

[13] He, S., Kuo, Y. \& Wu, D., Incorporating institutional and spatial factors in the selection of the optimal locations of public electric vehicle charging facilities: A case study of Beijing, China. Transportation Research Part C, 67, pp. 131-148, 2016.

[14] Sweda, T. \& Klabjan, D., An agent-based decision support system for electric vehicle charging infrastructure deployment. IEEE Vehicle Power and Propulsion Conference, 12339422, 2011. DOI: 10.1109/VPPC.2011.6043201.

[15] Ge, S., Feng, L., Liu, H. \& Wang, L., The planning of electric vehicle charging stations in the urban area. International Conference on Electronic \& Mechanical Engineering and Information Technology, 356, 2012. DOI: 10.2991/emeit.2012.356.

[16] Chen, C. \& Hua, G., A new model for optimal deployment of electric vehicle charging and battery swapping stations. International Journal of Control and Automation, 7, pp. 247-258, 2014.

[17] Wolbertus, R. \& Hoed, R., Electric vehicle fast charging needs in cities and along corridors. World Electric Vehicle Journal, 10, pp. 45-54, 2019.

[18] Cruz-Zambrzno, M., Corchero, C. \& Igualada-Gonzalez, L., Optimal location of fast charging stations in Barcelona: A Flow-Capturing approach. 10th International Conference on the European Energy Market, 13797585, 2013.

DOI: 10.1109/EEM.2013.6607414. 